\title{
The Impact of the Urban Heat Island during an Intense Heat Wave in Oklahoma City
}

\author{
Jeffrey B. Basara, ${ }^{1}$ Heather G. Basara, ${ }^{2}$ Bradley G. Illston, ${ }^{1}$ and Kenneth C. Crawford ${ }^{1}$ \\ ${ }^{1}$ Oklahoma Climatological Survey, University of Oklahoma, Norman, OK 73072, USA \\ ${ }^{2}$ Center for Applied Social Research, University of Oklahoma, Norman, OK 73072, USA \\ Correspondence should be addressed to Jeffrey B. Basara, jbasara@ou.edu
}

Received 29 May 2009; Revised 1 October 2009; Accepted 10 January 2010

Academic Editor: Sue Grimmond

Copyright (C) 2010 Jeffrey B. Basara et al. This is an open access article distributed under the Creative Commons Attribution License, which permits unrestricted use, distribution, and reproduction in any medium, provided the original work is properly cited.

\begin{abstract}
During late July and early August 2008, an intense heat wave occurred in Oklahoma City. To quantify the impact of the urban heat island (UHI) in Oklahoma City on observed and apparent temperature conditions during the heat wave event, this study used observations from 46 locations in and around Oklahoma City. The methodology utilized composite values of atmospheric conditions for three primary categories defined by population and general land use: rural, suburban, and urban. The results of the analyses demonstrated that a consistent UHI existed during the study period whereby the composite temperature values within the urban core were approximately $0.5^{\circ} \mathrm{C}$ warmer during the day than the rural areas and over $2^{\circ} \mathrm{C}$ warmer at night. Further, when the warmer temperatures were combined with ambient humidity conditions, the composite values consistently revealed even warmer heat-related variables within the urban environment as compared with the rural zone.
\end{abstract}

\section{Introduction}

Within the United States, heat waves are the most prominent cause of weather-related human mortality [1] and have been well studied by the public health community [2]. In recent years, the effects of heat waves had devastating impacts both in the United States $[1,3]$ and Europe [4-6]. The excess all cause mortality related to the August 2003 heat wave in Europe (estimated 22,000 to 45,000 heat-related deaths in 2 weeks across Europe) calls dramatic attention to the relationship between heat waves and health [7].

Children, elderly persons, those with chronic diseases such as cardiovascular and respiratory diseases, low income and minority groups, and individuals living alone are particularly vulnerable to excessive heat $[2,8,9]$. Unfortunately, the frequency, intensity, and impacts of heat waves will likely increase during future decades $[10,11]$. As a result, many cities have implemented heat watch-warning technologies to mitigate the impacts of heat waves and protect the populations of large urban areas [12-14].

In general, the atmospheric processes associated with heat waves involve significant, mid-tropospheric anomalies which subsequently produce extended periods of subsidence, clear skies, light winds, warm-air advection, and prolonged above normal temperature $[11,15,16]$. As such, heat waves impact large geographic areas. Yet, during two-heat-wave events in the central portion of the United States, approximately $65 \%$ of all heat-related deaths in 1995 occurred in Chicago [15] and, during 1999, approximately $80 \%$ of all deaths occurred in metropolitan areas (including Cincinnati, Chicago, Kansas City, Milwaukee, and St. Louis; [16]). Similarly, excessive heat-related deaths occurred throughout many European cities during the 2003 heat wave [4, 17-19].

The impact of urban environments on human health has become a critical issue facing the global society as the number and percentage of humans living in urban areas continues to grow [20-22]. Because direct and indirect weather-related accidents and deaths have continued to increase [23], the impact of environmental hazards combined with increased urbanization deserves intense study. It is well understood that urban areas have a profound impact on the local atmospheric conditions. In particular, the urban heat island (UHI) yields increased temperatures within the urban zone when compared to surrounding rural areas [24] and has 
many causative factors including differential thermal storage between urban and rural areas, decreased atmospheric moisture over urban zones due to limited evapotranspiration and increased runoff, increased anthropogenic heat flux, decreased terrestrial radiation loss, decreased total turbulent heat transport, and increased downwelling longwave radiation due to increased particulates and greenhouse gases [25]. Further, the UHI is most noticeable at night and under synoptic high pressure systems with calm conditions and clear skies [24, 26-28], and the UHI has been measured in cities spanning many varying climate regimes and sizes [2932].

Unfortunately, the collection of consistent, research quality observations of atmospheric state variables are limited in many urban areas. Kunkel et al. [15] noted that while the UHI is well documented, little information exists concerning urban heat islands during extensive heat wave events such as the one that impacted Chicago in 1995. At the same time, there is increased understanding that critical relationships exist between heat wave events, urban heat islands, and human mortality $[16,33,34]$. Yet, while numerous studies have surmised that the urban heat island has played a critical role in modulating environmental conditions during heat wave events [35-37], an overall lack of sufficient, researchquality data during the events has inhibited a thorough understanding of UHI, heat wave interactions.

During 2007 and 2008, a dense network of atmospheric monitoring sites were deployed across the Oklahoma City metropolitan area: the Oklahoma City Micronet (OKCNET). During late July and early August 2008, an intense heat wave impacted central Oklahoma including Oklahoma City and surrounding areas. Recent results from a study by Basara et al. [38] demonstrated a pronounced UHI signature in Oklahoma City whereby temperature values were typically greater than $1.5^{\circ} \mathrm{C}$ warmer at night and over $0.5^{\circ} \mathrm{C}$ warmer during the day in the urban zone versus the surrounding rural areas. Thus, given the dense meteorological observations across the Oklahoma City metropolitan area and the known presence of an UHI in Oklahoma City, the objectives of this study were (1) to quantify the impact of the UHI in Oklahoma City on environmental conditions during the heat wave event and (2) demonstrate how the UHI exacerbated heat conditions critical to human health.

\section{Data and Methods}

Oklahoma City is the largest city in the United States that is not a consolidated city-county (approximately $1610 \mathrm{~km}^{2}$ ). The urbanized area of Oklahoma City is approximately $630 \mathrm{~km}^{2}$ and has a well-defined central business district (approximately $20 \mathrm{~km}^{2}$ ) with buildings to $120 \mathrm{~m}$ in height.

This study utilized two main datasets collected from 15 July through 15 August 2008, which span the period prior to, during, and following the heat wave event. These datasets included observations collected from the Oklahoma City Micronet (OKCNET) as well as observations from 10 Oklahoma Mesonet sites in the Oklahoma City metropolitan area and the surrounding rural terrain.

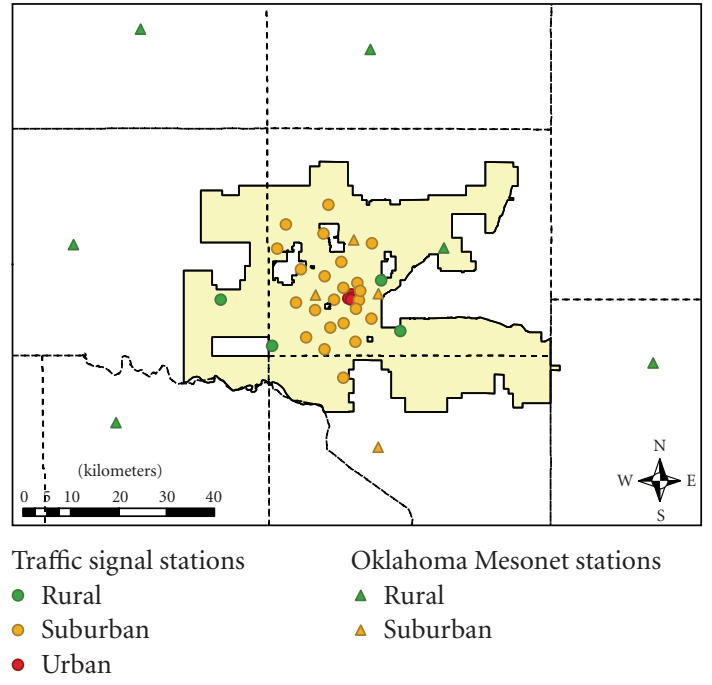

FIGURE 1: The locations of Oklahoma City Micronet and Oklahoma Mesonet sites used as part of the study. The highlighted area (tan) represents the municipal boundaries for the City of Oklahoma City and the dashed lines represent county borders. The urban sites consisted of locations classified by UCZ1 and UCZ2 [40], the suburban areas included sites classified as UCZ3 through UCZ6, and the rural sites included locations with limited structures consisting mainly of large expanses of native, short grass vegetation, interspersed trees, rangeland, and cropland (winter wheat).

2.1. The Oklahoma Mesonet. The Oklahoma Mesonet is an automated network of 120 remote, meteorological stations across Oklahoma [39]. Each station measures core parameters that include air temperature and relative humidity at $1.5 \mathrm{~m}$, wind speed and direction at $10 \mathrm{~m}$, atmospheric pressure, downwelling solar radiation, rainfall, and bare and vegetated soil temperatures at $10 \mathrm{~cm}$ below ground level. In addition, over 100 sites measure air temperature at $9 \mathrm{~m}$. In an effort to avoid anthropogenic influences, most Oklahoma Mesonet sites are located in rural areas. Mesonet data are collected and transmitted to a central point every 5 minutes where they are quality controlled, distributed, and archived [39]. This study used data collected from the ten sites in and around the Oklahoma City metropolitan area in 2008 (Figure 1).

2.2. The Oklahoma City Micronet. The Oklahoma City Micronet (OKCNET) is an operational network designed to improve atmospheric monitoring across the Oklahoma City metropolitan area [41]. The 40-station network consists of four Oklahoma Mesonet Stations (OKCE, OKCN, OKCW, and SPEN) and 36 stations mounted on traffic signals at a height of approximately $9 \mathrm{~m}$ and station spacing of approximately $3 \mathrm{~km}$. At each traffic signal site, atmospheric conditions of air temperature, humidity, pressure, rainfall, wind speed, and wind direction are measured and transmitted every minute to a central facility 24 hours per day, yearround where they are quality controlled, distributed, and archived using the Oklahoma Mesonet infrastructure. The Oklahoma City Micronet includes a cluster of stations within 
the central business district as well as stations throughout the Metropolitan area (Figure 1).

2.3. The Urban Heat Island Index. To quantify the varying environmental conditions that existed between the urban and rural zones in and around Oklahoma City during the heat wave in late July and early August 2008, the magnitude of the UHI was calculated during the study period. Typically, the determination of UHI intensity is limited according to the availability of observations and, when a limited number of observation sites are present, UHI intensity is often estimated using the difference between urban and rural temperatures from individual observing locations [42]. However, when multiple observation sites are available, UHI intensity can be calculated as the difference between mean urban and mean rural temperatures [38, 43]. Such computations provide a more robust measure of UHI intensity and minimize the inherent variability between observing sites that can impact the magnitude of UHI values $[30,38]$.

To complete the analysis of the UHI using the composite approach, sites were examined and grouped into one of three categories based on the surrounding land cover characteristics: urban, suburban, and rural (Figure 1). Table 1. shows the assigned surface characteristics for the stations included in the study along with the associated urban climate zone (UCZ) classifications defined by Oke [40]. Additional information regarding the siting and representativeness of the OKCNET stations is included in Basara et al. [41], while Schroeder and Basara [44] document the methodology used to determine the UCZ classifications of OKCNET sites.

The urban stations included nine OKCNET sites located within the central business district of Oklahoma City and were consistent with UCZ classifications of UCZ1 and UCZ2. The rural sites included a mixture of ten OKCNET and Oklahoma Mesonet stations at locations with limited structures consisting mainly of large expanses of native, short grass vegetation, interspersed trees, rangeland, and cropland (winter wheat). The third category, suburban in nature, comprised 28 locations (OKCNET and Mesonet stations) in areas with residential, commercial, and industrial structures consistent with UCZ classifications of UCZ3 through UCZ7 [40].

To determine the magnitude of the UHI for the urban core of Oklahoma City (i.e., "Urban" in Figure 1), a composite index value was used:

$$
\mathrm{HII}_{U}=T_{U}-T_{R},
$$

where $\mathrm{HII}_{U}$ is the heat island intensity of the composite urban values, $T_{U}$ is the mean temperature of the urban observations at $9 \mathrm{~m}$, and $T_{R}$ is the mean temperature of the rural observations at $9 \mathrm{~m}$. A similar calculation was completed for the suburban conditions:

$$
\mathrm{HII}_{S}=T_{S}-T_{R} \text {, }
$$

where $\mathrm{HII}_{S}$ is the heat island intensity of the composite suburban zone, $T_{S}$ is the mean temperature of the suburban observations at $9 \mathrm{~m}$, and $T_{R}$ is the mean temperature of the rural observations at $9 \mathrm{~m}$.
2.4. Formulations of Apparent Temperature. Because numerous studies have linked the impact of environmental conditions, including heat, to mortality [1, 3, 45-48], the composite $\mathrm{UHI}$ values $\left(\mathrm{HII}_{U}\right.$ and $\left.\mathrm{HII}_{S}\right)$ were combined with observed values of humidity and wind speed to compute traditional values used to estimate heat stress. Humidity and wind speed contribute to heat stress and several approaches have been used to estimate thermal stress in previous mortality studies. These include heat index $[49,50]$, the formulation of the Weather Stress Index (relative apparent temperature) by Kalkstein and Valimont [51] (KV86), a revised version of relative apparent temperature by Michelozzi et al. [52] (M07), and the Humidex [53].

The Weather Stress Index [51] is a summer season algorithm and is a derived form of apparent temperature (AT):

$$
\mathrm{AT}=-2.653+\left(0.994 T_{a}\right)+0.368\left(T_{d}\right)^{2},
$$

where $T_{a}=$ air temperature $\left({ }^{\circ} \mathrm{C}\right) ; T_{d}=$ dewpoint temperature $\left({ }^{\circ} \mathrm{C}\right)$.

The KV86 apparent temperature is corrected for wind using an adjustment table from Steadman [49]. Generally, if the apparent temperature exceeds $34^{\circ} \mathrm{C}$, winds tend to increase heat flow, thus raising the apparent temperature further.

A revised version of KV86 was developed by Michelozzi et al. [52]. Their formula for apparent temperature is similar to KV86 with the exception that it is not corrected for varying wind speeds:

$$
\mathrm{AT}=-2.653+\left(0.994 T_{a}\right)+0.0153\left(T_{d}\right)^{2},
$$

where AT $=$ apparent temperature $\left({ }^{\circ} \mathrm{C}\right), T_{a}=$ air temperature $\left({ }^{\circ} \mathrm{C}\right)$, and $T_{d}=$ dew point temperature $\left({ }^{\circ} \mathrm{C}\right)$.

The Humidex [53] has also been used to study the consequences of heat waves on health [54] and is based on the work of Masterton and Richardson [55]. This algorithm uses a slightly different formulation and includes an interpretation that is directly related to heat stress:

$$
\text { Humidex }=T+\frac{5}{9(e-10)},
$$

where $T$ is the air temperature $\left({ }^{\circ} \mathrm{C}\right)$ and $e$ is the vapor pressure. The Humidex values correspond to the following categories of comfort.

Comfortable: $H<27$.

Some discomfort: $27 \leq H<30$.

Great discomfort: $30 \leq H<40$.

Dangerous: $40 \leq H<55$.

Very dangerous: $H \geq 55$ (heatstroke imminent).

\section{Results}

During the waning days of July 2008, a heat wave event began to build across central Oklahoma with the most intense conditions spanning 31 July through 5 August 2008 (hereafter referred to as the "heat wave period"). Daily maximum temperatures across the region were $5-8^{\circ} \mathrm{C}$ warmer 
TABLE 1: The surface characteristics of stations used in the study along with urban climate zone classifications defined by Oke [40].

\begin{tabular}{|c|c|c|}
\hline Site & Surface Type & $\begin{array}{l}\text { Urban climate zone } \\
\text { classification; Oke [40] }\end{array}$ \\
\hline KCB101 & Urban & UCZ2 \\
\hline KCB102 & Urban & UCZ2 \\
\hline KCB103 & Urban & UCZ1 \\
\hline KCB104 & Urban & UCZ1 \\
\hline KCB105 & Urban & UCZ1 \\
\hline KCB106 & Urban & UCZ1 \\
\hline KCB107 & Urban & UCZ2 \\
\hline KCB108 & Urban & UCZ1 \\
\hline KCB109 & Urban & UCZ2 \\
\hline KCB110 & Suburban & UCZ6 \\
\hline KSW101 & Rural & NA \\
\hline KSW102 & Suburban & UCZ6 \\
\hline KSW103 & Suburban & UCZ4 \\
\hline KSW104 & Suburban & UCZ6 \\
\hline KSW105 & Suburban & UCZ4, UCZ7 \\
\hline KSW106 & Suburban & UCZ4, UCZ5 \\
\hline KSW107 & Suburban & UCZ4 \\
\hline KSW108 & Suburban & UCZ6 \\
\hline KSW109 & Suburban & UCZ5 \\
\hline KSW110 & Rural & NA \\
\hline KSW111 & Suburban & UCZ5, UCZ6 \\
\hline KSW112 & Suburban & UCZ5, UCZ6 \\
\hline KSE101 & Suburban & UCZ4, UCZ6 \\
\hline KSE102 & Rural & NA \\
\hline KNW101 & Suburban & UCZ4 \\
\hline KNW102 & Suburban & UCZ7 \\
\hline KNW103 & Suburban & UCZ4 \\
\hline KNW104 & Suburban & UCZ7 \\
\hline KNW105 & Suburban & UCZ4, UCZ6 \\
\hline KNW106 & Suburban & UCZ4 \\
\hline KNW107 & Suburban & UCZ4 \\
\hline KNW108 & Suburban & UCZ4 \\
\hline KNE101 & Suburban & UCZ7 \\
\hline KNE102 & Suburban & UCZ4 \\
\hline KNE103 & Rural & $\mathrm{NA}$ \\
\hline KNE104 & Suburban & UCZ4 \\
\hline KNE105 & Suburban & UCZ4 \\
\hline ELRE & Rural & NA \\
\hline GUTH & Rural & NA \\
\hline KING & Rural & NA \\
\hline MINC & Rural & NA \\
\hline NRMN & Suburban & UCZ7 \\
\hline OKCN & Suburban & UCZ7 \\
\hline OKCE & Suburban & UCZ6 \\
\hline OKCW & Suburban & UCZ7 \\
\hline SHAW & Rural & NA \\
\hline SPEN & Rural & NA \\
\hline
\end{tabular}




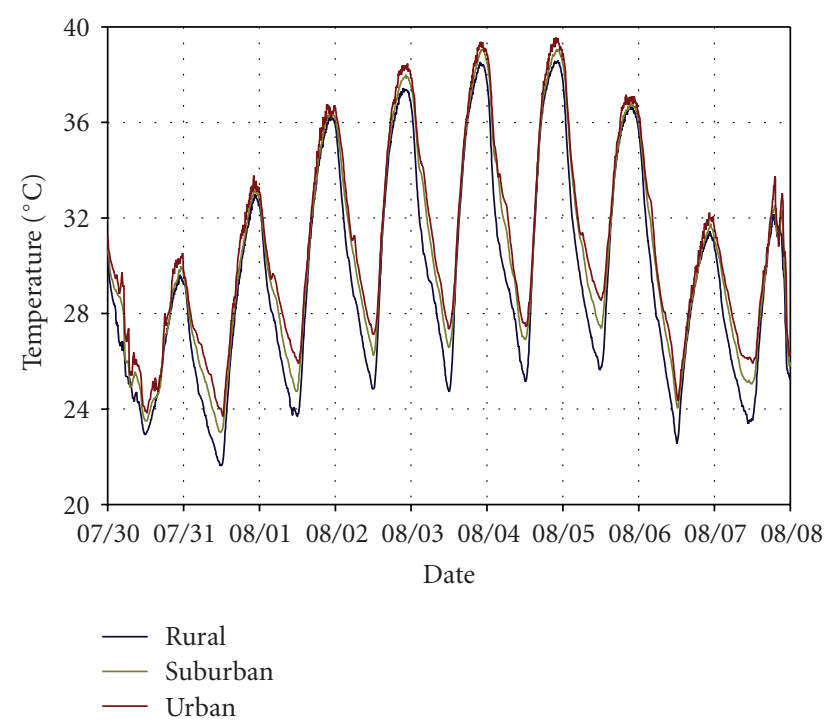

(a)

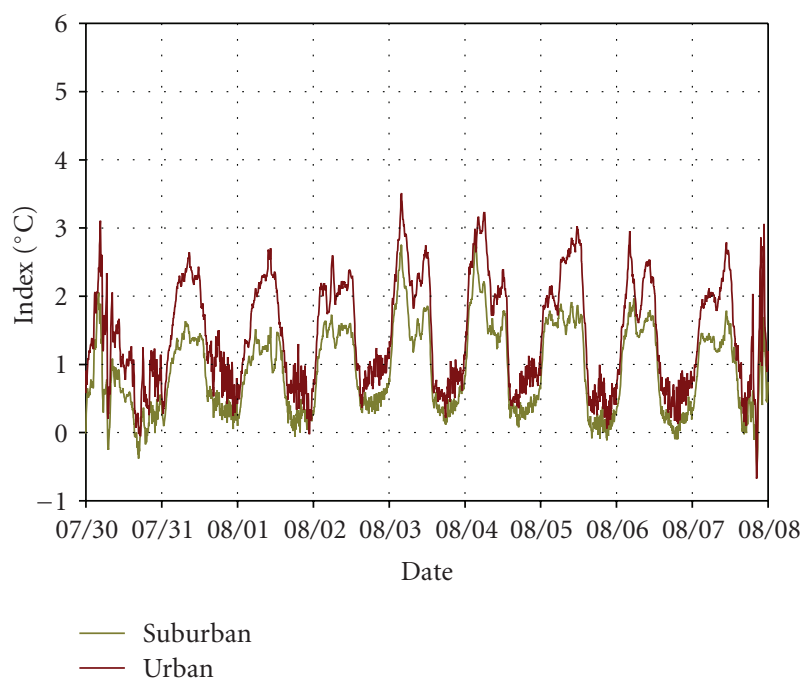

(b)

Figure 2: (a) Composite urban (red), suburban (gold), and rural (blue) values of air temperature from 30 July 2008 to 8 August 2008. (b) Composite diurnal values of urban heat island intensity with respect to rural composite values for the urban (red) and suburban (gold) locations.

than the typical climatological values and approached or exceeded $40^{\circ} \mathrm{C}$ during the heat wave. The composite air temperature values for rural, suburban, and urban zones for Oklahoma City, shown in Figure 2(a), reveal the increasing temperature trend from late July through early August as the heat wave intensified. Further, the official observing station for Oklahoma City (Will Rogers World Airport) observed record high temperatures of $41^{\circ} \mathrm{C}\left(106^{\circ} \mathrm{F}\right)$ on 3 and 4 August 2008 , the latter breaking a record that had stood for 90 years. Thus, the most intense portion of the heat wave represented historic conditions for the period.

A consistent UHI occurred during the heat wave period as demonstrated in Figure 2(b) whereby conditions in the urban core of Oklahoma City were (a) typically $0.5^{\circ} \mathrm{C}$ warmer during the day, (b) more than $2^{\circ} \mathrm{C}$ warmer at night and, (c) were consistent with UHI intensities noted by Basara et al. [38]. At the same time, the suburban areas also displayed a warmer signal than the rural areas, especially during the overnight periods when conditions were typically $1.5^{\circ} \mathrm{C}$ or more warmer.

Prior to the onset of the heat wave period, light precipitation occurred in central Oklahoma on 29 and 30 July. As a result, the combination of the elevated temperatures, local evapotranspiration, and a relatively moist airmass (Figure 3) produced elevated heat index values from 31 July through 6 August. The impact of such features, especially from 31 July through 2 August, can be seen in Figures 4(a) and 4(b), which incorporate the temperature and UHI intensity analyses from Figures 2(a) and 2(b) with associated humidity data, collected at the observing sites. Thus, the result of the increased humidity during the onset of the heat wave period yielded overall increased magnitudes of heat index (Figure 4(a)) when compared with air temperature (Figure 2(a)). Further, the impact of the UHI generated composite heat index values in the urban core (suburban) that were typically $1^{\circ} \mathrm{C}\left(0.5^{\circ} \mathrm{C}\right)$ or more warmer than the rural areas during the day and more than $5^{\circ} \mathrm{C}\left(3^{\circ} \mathrm{C}\right)$ warmer at night (Figure $4(\mathrm{~b})$ ).

Evaluation of the multivariate Humidex (Figure 5) further underscores the importance of elevated humidity combined with elevated temperature during the onset of the heat wave period. As such, while daytime Humidex values climbed into the "Dangerous" category for six consecutive days, the greatest Humidex values occurred during the afternoon on 2 August prior to the record breaking heat on 3 and 4 August. However, as the heat wave period progressed, the airmass became less moist as the humidity decreased; thus, the UHI Heat Index values decreased and became similar in magnitude to the observed UHI intensity values.

Finally, to further demonstrate the robustness of the results, values of relevant apparent temperature according to KV86 (Figure 6), and apparent temperature by M07 (Figures $7(\mathrm{a})$ and $7(\mathrm{~b})$ ) were analyzed. While the magnitudes of KV86 and M07 differ for the period (the peak values of KV86 tended to be approximately $4^{\circ} \mathrm{C}$ warmer than M07), both showed similar trends during the heat wave period. The values of KV86 and M07 steadily increased from 31 July through the period until reaching a maximum on 5 August. Further, both analyses demonstrate a consistent pattern whereby urban (suburban) temperature values were approximately $1^{\circ} \mathrm{C}\left(0.5^{\circ} \mathrm{C}\right)$ warmer than the rural areas during the day and $2^{\circ} \mathrm{C}\left(1^{\circ} \mathrm{C}\right)$ or warmer at night.

\section{Discussion}

The purpose of this study was to quantify the impact of the UHI from Oklahoma City during an intense heat wave that occurred in late July and early August 2008. The heat wave period lasted approximately one week and produced record maximum temperature values at the official meteorological observing site for Oklahoma City on 3 and 4 August 2008. 


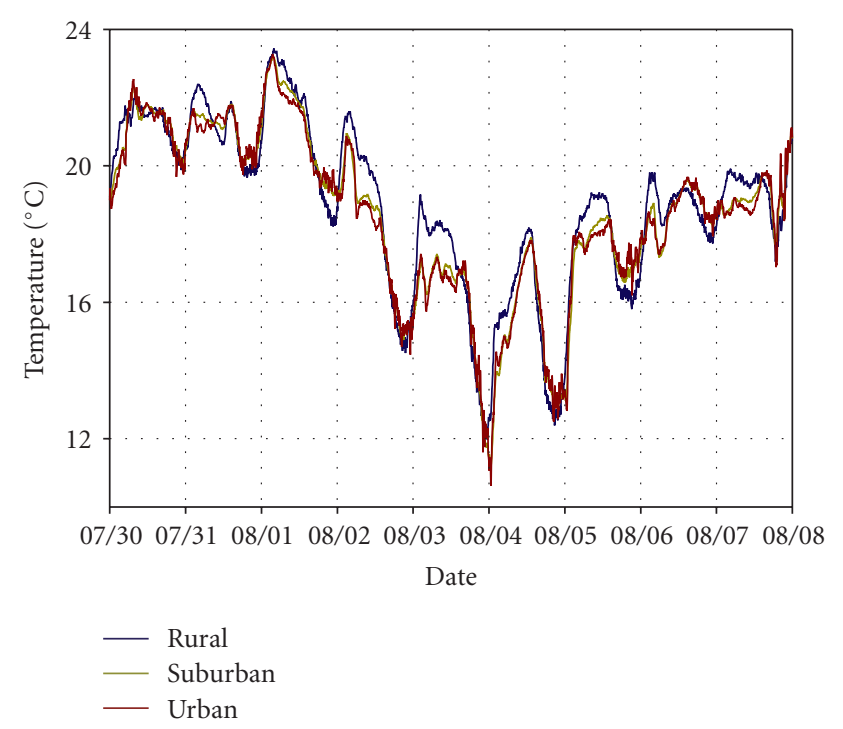

Figure 3: Composite urban (red), suburban (gold), and rural (blue) values of dew point temperature from 30 July 2008 to 8 August 2008.

Unfortunately, the airport-observing site, located approximately $10 \mathrm{~km}$ southwest of the central business district, is not representative of the larger Oklahoma City metropolitan area. This results from the airport being located on the rural/suburban interface with surrounding conditions that are mainly rural in land use. However, the Oklahoma City Micronet and the Oklahoma Mesonet provided not only increased observations within the urban and rural environments, but the observation sites spanned varying land-surface characteristics associated with varying land use.

Thus, this study focused on utilizing composite analyses for urban, suburban, and rural using observations from 46 locations comprising Oklahoma City Micronet and Oklahoma Mesonet stations. The robust composite analyses of temperature and the various formulations of apparent temperature (heat index, KV86, M07), consistently demonstrated that the urban core of Oklahoma City was significantly warmer than the surrounding rural areas throughout the diurnal cycle. Though not as warm as the urban core, the suburban areas were also warmer than the surrounding rural zones.

This latter result further demonstrates the complexities in quantifying the role of the UHI on heat wave events. In general, observations from within the urban core of a city are not available. As such, in situ temperature measurements from locations nearby (e.g., airports) are often used to represent the "urban" portion of the city. In other cases, airport measurements may be used to represent the rural locations due to a lack of observations within the rural zone. However, this study demonstrates that simple urban-versus rural comparisons neglect a critical component to the atmospheric processes in and around cities: from a composite temperature standpoint, the urban core is fundamentally different than either the rural and suburban (or transition) zones.

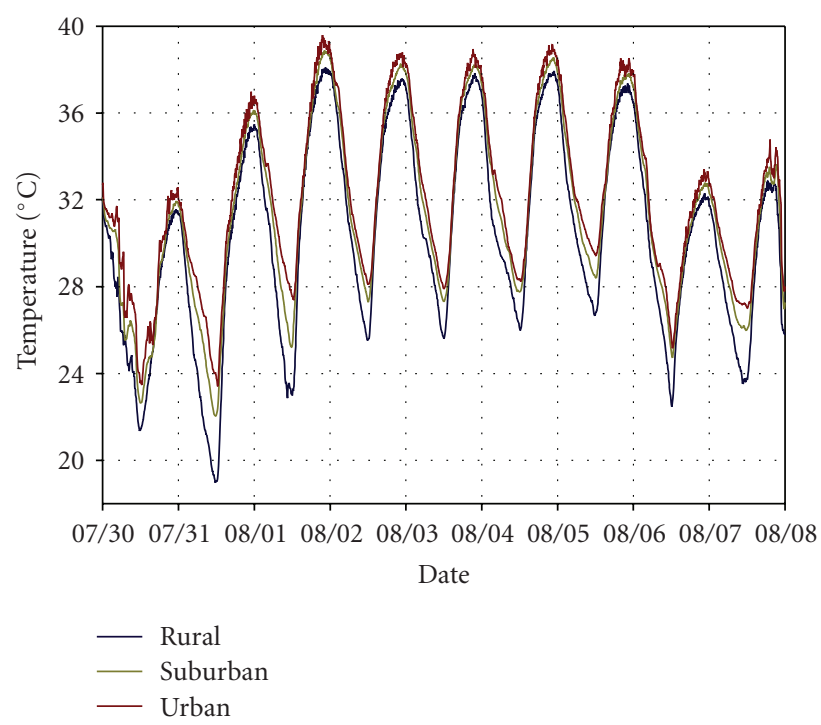

(a)

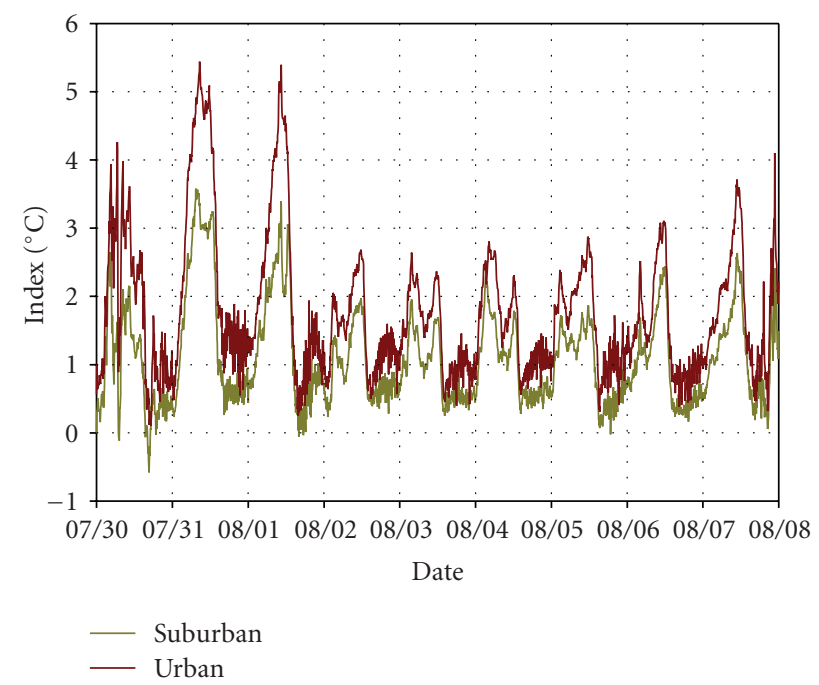

(b)

Figure 4: (a) Composite urban (red), suburban (gold), and rural (blue) values of computed heat index $[48,49]$ from 30 July 2008 to 8 August 2008. (b) Composite diurnal values of UHI Heat Index with respect to rural composite values for the urban (red) and suburban (gold) locations. The methodology is consistent with the analysis demonstrated in Figure 2(b) and computed values of the heat index $[48,49]$.

In Oklahoma City, the airport observing sites, as well as much of the metropolitan population, reside in the suburban zone. However, the impact of the UHI is critically relevant to residents in and near the urban core. In many cases, the urban core is populated by economically disadvantaged, elderly, and minority racial groups, which are considered to disproportionately bear the greatest burdens with regard to adverse health outcomes $[8,56,57]$. Additionally, housing is typically older, includes a high number of renter occupied units, and is less likely to be adequately air-conditioned; such housing conditions further exacerbate the risk of illness 


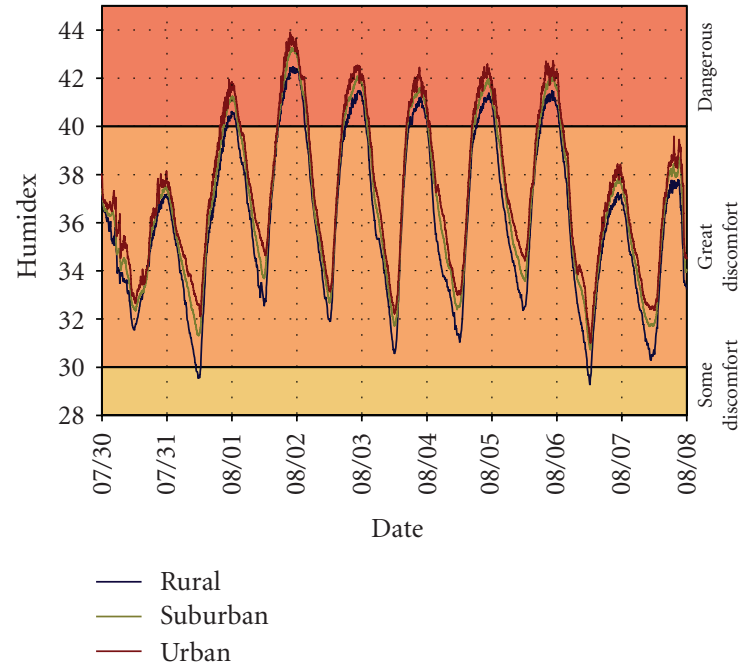

Figure 5: Composite urban (red), suburban (gold), and rural (blue) Humidex values and associated reference categories from 30 July 2008 to 8 August 2008.

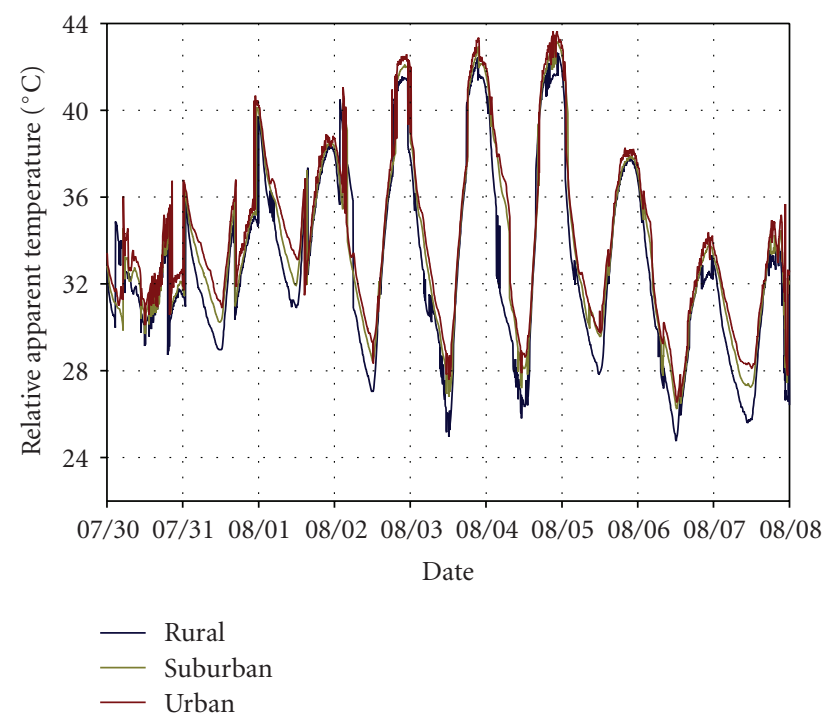

Figure 6: Composite urban (red), suburban (gold), and rural (blue) values of relative apparent temperature (KV86) from 30 July 2008 to 8 August 2008.

and death due to extreme heat events $[8,58-60]$. Thus, the differences in composite temperatures between urban, suburban, and rural zones along with a lack of representative measurements characterizing atmospheric conditions within the UHI becomes an important result when human impacts are considered. Because warning decisions and intervention planning are typically dependent upon airport measurements, the vulnerable population residing within the urban core is at increased risk. The decisions to implement heat warnings are a function of atmospheric observations mainly collected at airport sites that are more consistent with the suburban environment, where less severe heat conditions occur. In other words, severe heat conditions (i.e., those

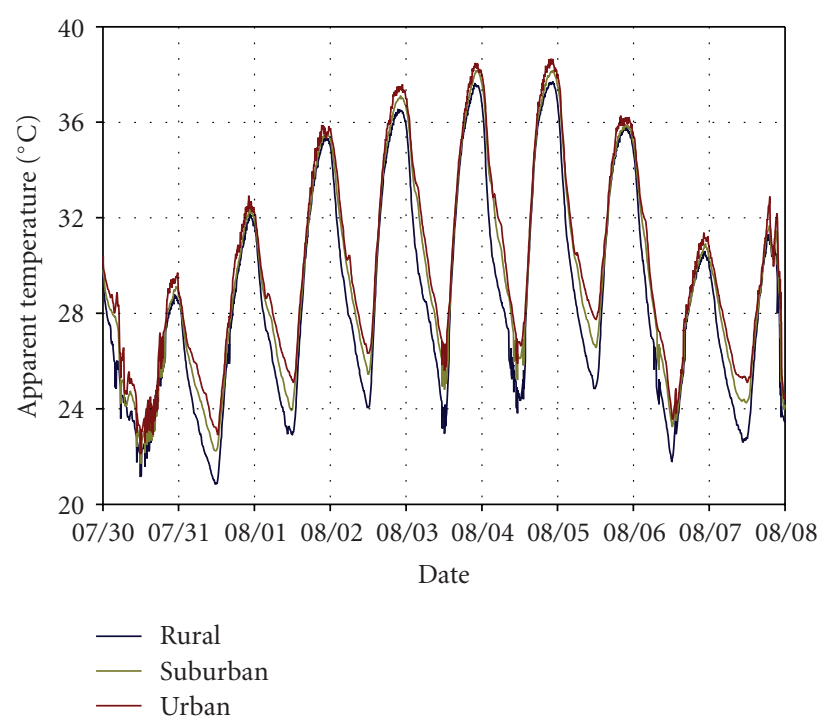

(a)

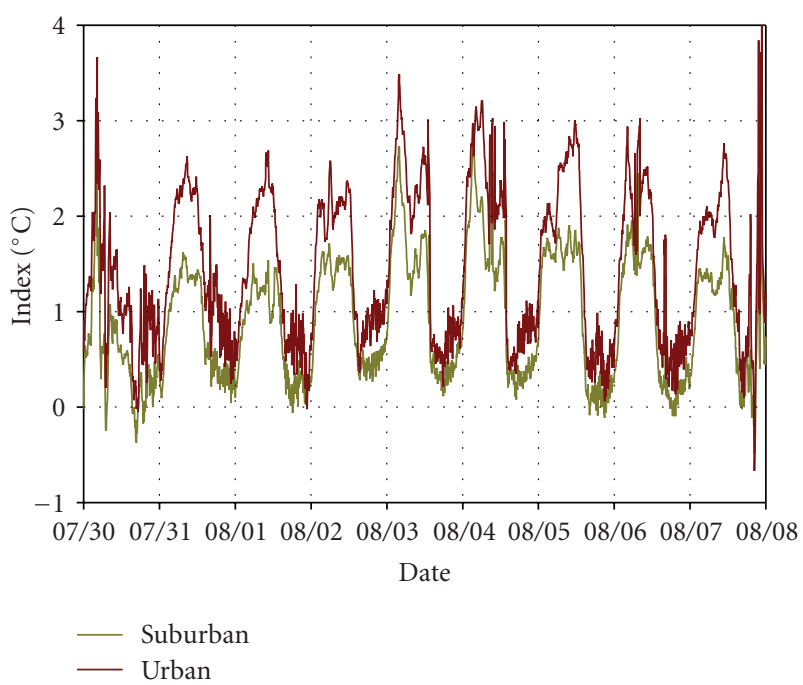

(b)

Figure 7: (a) Composite urban (red), suburban (gold), and rural (blue) values of relative apparent temperature (M07) from 30 July 2008 to 8 August 2008. (b) Composite diurnal values of relative apparent temperature (M07) with respect to rural composite values for the urban (red) and suburban (gold) locations.

exceeding critical heat thresholds) may be ongoing in the urban core prior to those critical thresholds being met in the suburban zone.

This study also demonstrated that other factors contributed to the overall impact of the urban zone on the heat wave event. Increased ambient humidity at the onset of the heat wave period coupled with the UHI produced increased apparent temperature (heat index, KV86, M07) and Humidex at the beginning of the period. During the heat wave period, the number of minutes the urban areas experienced temperatures considered "Dangerous" according to the Humidex was 3430 compared to 3005 for suburban and 2525 for the rural zones. Further, during the overnight 
periods spanning 31 July to 2 August, the UHI Heat Index values were considerably warmer than the rural areas.

Karl and Knight [61] noted that a significant contributor to the number of deaths during the Chicago heat wave in 1995 was likely a result of increased nighttime values of apparent temperature. While nocturnal atmospheric conditions were not as extreme during the 2008 event in Oklahoma City as Chicago in 1995, the results of this study revealed that, at night, apparent temperatures in the urban core were significantly greater than the surrounding rural areas. In particular, the greatest differences occurred early in the heat wave period when the ambient humidity was greatest. The elevated apparent temperature was likely due in, in part, to fact that as the urban areas cooled versus the rural zones, the temperature in rural areas cooled more rapidly due to radiative and in situ cooling [62] such that the heat index was negligible, regardless of humidity. However, because the urban zone cooled at a slower rate due to increased thermal storage and impervious fraction, decreased sky view factor, and increased anthropogenic heating, among other possible factors, the temperatures remained warmer overall and the apparent temperature remained elevated during the nocturnal period. Thus, the apparent temperature values were much warmer than those in rural areas. While temperatures were somewhat less during the onset of the heat wave period than during the most intense conditions, the UHI combined with humidity created temperatures in the urban core that "felt" significantly warmer and provided much less relief to individuals living in that environment.

\section{Conclusions}

To date, the overall health impacts of the heat wave in Oklahoma City in 2008, remain uncharacterized because health information at coincident spatial and temporal scales are not yet available. However, from a temperature standpoint, the urban heat island of Oklahoma City exacerbated an event that, in general, produced historic heat for the period by (a) revealing the true intensity of heat during the daytime within the suburban and urban zones and (b) by increasing the minimum temperature values. Overall, the results of the analyses demonstrated that a consistent UHI existed during the study period whereby the composite temperature values and computed apparent temperatures within the urban core (suburban zone) were approximately 1 to $2^{\circ} \mathrm{C}\left(0.5\right.$ to $\left.1.5^{\circ} \mathrm{C}\right)$ warmer during the day than the rural areas and over $3^{\circ} \mathrm{C}$ $\left(2^{\circ} \mathrm{C}\right)$ warmer at night. The implications are that individuals living in the urban zone experience increased heat and potential risks for heat-related illness more so than those in rural areas due to the combined impacts of the UHI and the heat wave event.

Finally, it should be noted that a limitation to this study is actually one of its strengths: composite analyses. While concisely illustrating the general differences between urban, suburban, and rural areas during the heat wave period, specific spatial information is not portrayed. Even so, without the dense observations included in this study via OKCNET and the Oklahoma Mesonet, such concise analyses focused on localized impacts of urban-atmosphere interactions would not be possible. Given the results of this study and new operational capabilities such as the Oklahoma City Micronet, new tools, and analysis techniques can be developed and applied in future studies to provide specific heat information at the neighborhood scale for use in more refined public health analyses and mitigation strategies.

\section{Acknowledgments}

Funding for the Oklahoma City Micronet and support for this study was provided by the Oklahoma State Regents for Higher Education (equipment), the Office of the Vice President for Research at the University of Oklahoma (personnel and supplies), the Oklahoma Mesonet (personnel), the Oklahoma Climatological Survey (personnel and inkind support), and the City of Oklahoma City (in-kind support). Oklahoma's taxpayers fund the Oklahoma Mesonet through the Oklahoma State Regents for Higher Education and the Oklahoma Department of Public Safety. In addition, the authors thank the anonymous reviewers who provided constructive criticism that improved the quality of this article.

\section{References}

[1] S. A. Changnon, K. E. Kunkel, and B. C. Reinke, "Impacts and responses to the 1995 heat wave: a call to action," Bulletin of the American Meteorological Society, vol. 77, no. 7, pp. 1497-1506, 1996.

[2] R. S. Kovats and S. Hajat, "Heat stress and public health: a critical review," Annual Review of Public Health, vol. 29, pp. 41-55, 2008.

[3] J. C. Semenza, C. H. Rubin, K. H. Falter, et al., "Heat-related deaths during the July 1995 heat wave in Chicago," New England Journal of Medicine, vol. 335, no. 2, pp. 84-90, 1996.

[4] S. Vandentorren, F. Suzan, S. Medina, et al., "Mortality in 13 French cities during the August 2003 heat wave," American Journal of Public Health, vol. 94, no. 9, pp. 1518-1520, 2004.

[5] T. Kosatsky, “The 2003 European heat waves," Euro Surveillance, vol. 10, no. 7, pp. 148-149, 2005.

[6] L. Grize, A. Huss, O. Thommen, C. Schindler, and C. BraunFahrländer, "Heat wave 2003 and mortality in Switzerland," Swiss Medical Weekly, vol. 135, no. 13-14, pp. 200-205, 2005.

[7] J. A. Patz, D. Campbell-Lendrum, T. Holloway, and J. A. Foley, "Impact of regional climate change on human health," Nature, vol. 438, no. 7066, pp. 310-317, 2005.

[8] S. L. Harlan, A. J. Brazel, L. Prashad, W. L. Stefanov, and L. Larsen, "Neighborhood microclimates and vulnerability to heat stress," Social Science and Medicine, vol. 63, no. 11, pp. 2847-2863, 2006.

[9] R. Basu, F. Dominici, and J. M. Samet, "Temperature and mortality among the elderly in the United States: a comparison of epidemiologic methods," Epidemiology, vol. 16, no. 1, pp. 58-66, 2005.

[10] M. Beniston, "The 2003 heat wave in Europe: a shape of things to come? An analysis based on Swiss climatological data and model simulations," Geophysical Research Letters, vol. 31, no. 2, Article ID L02202, 2004. 
[11] G. A. Meehl and C. Tebaldi, "More intense, more frequent, and longer lasting heat waves in the 21st century," Science, vol. 305, no. 5686, pp. 994-997, 2004.

[12] S. Sheridan and L. Kalkstein, "Heat watch-warning systems in urban areas," World Resource Review, vol. 10, pp. 375-383, 1998.

[13] K. L. Ebi, T. J. Teisberg, L. S. Kalkstein, L. Robinson, and R. F. Weiher, "Heat watch/warning systems save lives: estimated costs and benefits for Philadelphia 1995-98," Bulletin of the American Meteorological Society, vol. 85, no. 8, pp. 1067-1073, 2004.

[14] S. C. Sheridan and L. S. Kalkstein, "Progress in heat watchwarning system technology," Bulletin of the American Meteorological Society, vol. 85, no. 12, pp. 1931-1941, 2004.

[15] K. E. Kunkel, S. A. Changnon, B. C. Reinke, and R. W. Arritt, "The July 1995 heat wave in the midwest: a climatic perspective and critical weather factors," Bulletin of the American Meteorological Society, vol. 77, no. 7, pp. 1507-1518, 1996.

[16] M. A. Palecki, S. A. Changnon, and K. E. Kunkel, "The nature and impacts of the July 1999 heat wave in the midwestern United States: learning from the lessons of 1995," Bulletin of the American Meteorological Society, vol. 82, no. 7, pp. 13531367, 2001.

[17] H. Johnson, R. S. Kovats, G. McGregor, J. Stedman, M. Gibbs, and H. Walton, "The impact of the 2003 heat wave on daily mortality in England and Wales and the use of rapid weekly mortality estimates," Euro Surveillance, vol. 10, no. 7, pp. 168$171,2005$.

[18] P. Michelozzi, F. de Donato, L. Bisanti, et al., "The impact of the summer 2003 heat waves on mortality in four Italian cities," Euro Surveillance, vol. 10, no. 7, pp. 161-165, 2005.

[19] P. Pirard, S. Vandentorren, M. Pascal, et al., "Summary of the mortality impact assessment of the 2003 heat wave in France," Euro Surveillance, vol. 10, no. 7, pp. 153-156, 2005.

[20] United Nations Human Settlements Program, "Human Settlements Basic Statistics," 1997, http://www.unhabitat .org/unchs/english/stats/contents.htm.

[21] W. F. Dabberdt, J. Hales, S. Zubrick, et al., "Forecast issues in the urban zone: report of the 10th prospectus development team of the U.S. weather research program," Bulletin of the American Meteorological Society, vol. 81, no. 9, pp. 2047-2064, 2000.

[22] United Nations, "World Urbanization Prospects—2003 Revision," 2003, http://www.un.org/esa/population/publications/ wup2003/2003wup.htm.

[23] S. A. Changnon, "Inadvertent weather modification in urban areas: lessons for global climate change," Bulletin of the American Meteorological Society, vol. 73, no. 5, pp. 619-627, 1992.

[24] R. Bornstein, "Observations of the urban heat island effect in New York City," Journal of Applied Meteorology, vol. 7, pp. 575$582,1968$.

[25] S. Grimmond, "Urbanization and global environmental change: local effects of urban warming," Geographical Journal, vol. 173, no. 1, pp. 83-88, 2007.

[26] L. C. Nkemdirim, "A test of a lapse rate/wind speed model for estimating heat island magnitude in an urban airshed," Journal of Applied Meteorology, vol. 19, no. 6, pp. 748-756, 1980.

[27] T. R. Oke, "The urban energy balance," Progress in Physical Geography, vol. 12, no. 4, pp. 471-508, 1988.

[28] J. Lu and S. P. Arya, "A laboratory study of the urban heat island in a calm and stably stratified environment-part I: temperature field," Journal of Applied Meteorology, vol. 36, pp. 1377-1391, 1997.

[29] T. R. Oke, R. A. Spronken-Smith, E. Jáuregui, and C. S. Grimmond, "The energy balance of central Mexico City during the dry season," Atmospheric Environment, vol. 33, no. 24-25, pp. 3919-3930, 1999.

[30] T. W. Hawkins, A. J. Brazel, W. L. Stefanov, W. Bigler, and E. M. Saffell, "The role of rural variability in urban heat island determination for Phoenix, Arizona," Journal of Applied Meteorology, vol. 43, no. 3, pp. 476-486, 2004.

[31] C. J. G. Morris, I. Simmonds, and N. Plummer, "Quantification of the influence of wind and cloud on the nocturnal urban heat island of a large city," Journal of Applied Meteorology, vol. 40, no. 2, pp. 169-182, 2001.

[32] K. M. Hinkel, F. E. Nelson, A. E. Klene, and J. H. Bell, "The urban heat island in winter at Barrow, Alaska," International Journal of Climatology, vol. 23, no. 15, pp. 1889-1905, 2003.

[33] L. S. Kalkstein and R. E. Davis, "Weather and human mortality: an evaluation of demographic and interregional responses in the United States," Annals of the Association of American Geographers, vol. 79, no. 1, pp. 44-64, 1989.

[34] L. S. Kalkstein and J. S. Greene, "An evaluation of climate/mortality relationships in large U.S. cities and the possible impacts of a climate change," Environmental Health Perspectives, vol. 105, no. 1, pp. 84-93, 1997.

[35] C. Campetella and M. Rusticucci, "Synoptic analysis of an extreme heat wave over Argentina in March 1980," Meteorological Applications, vol. 5, no. 3, pp. 217-226, 1998.

[36] K. E. Smoyer-Tomic, R. Kuhn, and A. Hudson, "Heat wave hazards: an overview of heat wave impacts in Canada," Natural Hazards, vol. 28, no. 2-3, pp. 463-485, 2003.

[37] R. Basu and J. M. Samet, "Relation between elevated ambient temperature and mortality: a review of the epidemiologic evidence," Epidemiologic Reviews, vol. 24, no. 2, pp. 190-202, 2002.

[38] J. B. Basara, P. K. Hall Jr., A. J. Schroeder, B. G. Illston, and K. L. Nemunaitis, "Diurnal cycle of the Oklahoma City urban heat island," Journal of Geophysical Research D, vol. 113, no. 20, Article ID D20109, 2008.

[39] R. A. McPherson, C. A. Fiebrich, K. C. Crawford, et al., "Statewide monitoring of the mesoscale environment: a technical update on the Oklahoma Mesonet," Journal of Atmospheric and Oceanic Technology, vol. 24, no. 3, pp. 301321, 2007.

[40] T. R. Oke, Initial Guidance to Obtain Representative Meteorological Observations at Urban Sites, WMO/TD, no. 1250, 2004.

[41] J. B. Basara, B. G. Illston, C. A. Fiebrich, et al., "The Oklahoma City Micronet," Meteorological Applications. In press.

[42] B. Ackerman, "Temporal march of the Chicago heat island," Journal of Climate \& Applied Meteorology, vol. 24, no. 6, pp. 547-554, 1985.

[43] Y. Kim and J. Baik, "Spatial and temporal structure of the urban heat island in Seoul," Journal of Applied Meteorology, vol. 44, pp. 591-605, 2005.

[44] A. J. Schroeder and J. B. Basara, "Challenges associated with classifying urban meteorological stations: the Oklahoma City Micronet example," The Open Atmospheric Science Journal in review.

[45] R. E. Davis, P. C. Knappenberger, P. J. Michaels, and W. M. Novicoff, "Changing heat-related mortality in the United States," Environmental Health Perspectives, vol. 111, pp. 17121718, 2003. 
[46] S. Hajat, B. Armstrong, M. Baccini, et al., "Impact of high temperatures on mortality: is there an added heat wave effect?" Epidemiology, vol. 17, no. 6, pp. 632-638, 2006.

[47] H. Kan, S. J. London, H. Chen, et al., "Diurnal temperature range and daily mortality in Shanghai, China," Environmental Research, vol. 103, no. 3, pp. 424-431, 2007.

[48] S. N. Gosling, J. A. Lowe, G. R. McGregor, M. Pelling, and B. D. Malamud, "Associations between elevated atmospheric temperature and human mortality: a critical review of the literature," Climatic Change, vol. 92, no. 3-4, pp. 299-341, 2009.

[49] R. G. Steadman, "The assessment of sultriness-part I: a temperature-humidity index based on human physiology and clothing science," Journal of Applied Meteorology, vol. 18, no. 7, pp. 861-873, 1979.

[50] L. Rothfusz, "The heat index "equation" (or, more than you ever wanted to know about heat index)," Technical Attachment SR 90-23, NWS, 1990.

[51] L. S. Kalkstein and K. M. Valimont, "An evaluation of summer discomfort in the United States using a relative climatological index," Bulletin, vol. 67, no. 7, pp. 842-848, 1986.

[52] P. Michelozzi, U. Kirchmayer, K. Katsouyanni, et al., "Assessment and prevention of acute health effects of weather conditions in Europe, the PHEWE project: background, objectives, design," Environmental Health, vol. 6, article 12, 2007.

[53] S. Conti, P. Meli, G. Minelli, et al., "Epidemiologic study of mortality during the summer 2003 heat wave in Italy," Environmental Research, vol. 98, no. 3, pp. 390-399, 2005.

[54] A. Russo and L. Bisanti, "Heat wave effect on frail population in metropolitan Milano, Italy," Epidemiology, vol. 15, pp. 9798, 2004.

[55] J. M. Masterton and F. A. Richardson, Humidex: A Method of Quantifying Human Discomfort due to Excessive Heat and Humidity, Environment Canada, Atmospheric Environment Service, Ontario, Canada, 1979.

[56] F. C. Curriero, K. S. Heiner, J. M. Samet, S. L. Zeger, L. Strug, and J. A. Patz, "Temperature and mortality in 11 cities of the eastern United States," American Journal of Epidemiology, vol. 155, no. 1, pp. 80-87, 2002.

[57] M. S. O’Neill, A. Zanobetti, and J. Schwartz, "Modifiers of the temperature and mortality association in seven US cities," American Journal of Epidemiology, vol. 157, no. 12, pp. 10741082, 2003.

[58] M. A. McGeehin and M. Mirabelli, "The potential impacts of climate variability and change on temperature-related morbidity and mortality in the United States," Environmental Health Perspectives, vol. 109, supplement 2, pp. 185-189, 2001.

[59] M. O'Neill, "Air conditioning and heat-related health effects," Applied Environmental Science and Public Health, vol. 1, pp. 912, 2003.

[60] M. Medina-Ramon, A. Zanobetti, D. P. Cavanagh, and J. Schwartz, "Extreme temperatures and mortality: assessing effect modification by personal characteristics and specific cause of death in a multi-city case-only analysis," Environmental Health Perspectives, vol. 114, pp. 1331-1336, 2006.

[61] T. R. Karl and R. W. Knight, "The 1995 Chicago heat wave: how likely is a recurrence?" Bulletin of the American Meteorological Society, vol. 78, no. 6, pp. 1107-1119, 1997.

[62] E. D. Hunt, J. B. Basara, and C. R. Morgan, "Significant inversions and rapid in situ cooling at a well-sited Oklahoma mesonet station," Journal of Applied Meteorology and Climatology, vol. 46, no. 3, pp. 353-367, 2007. 

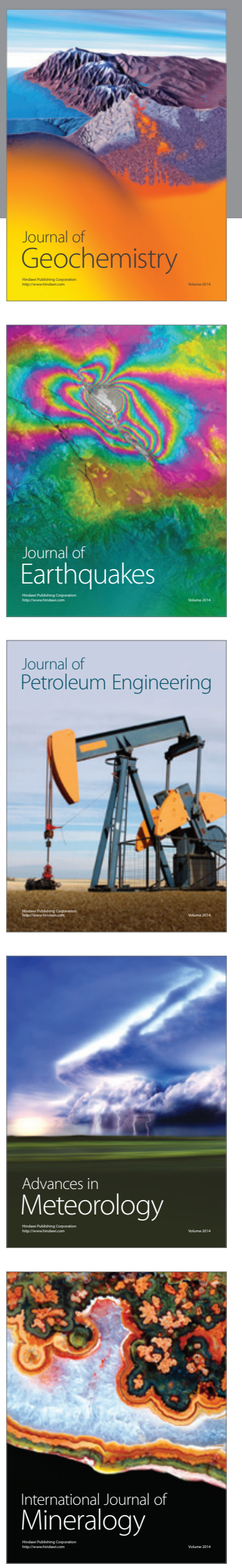
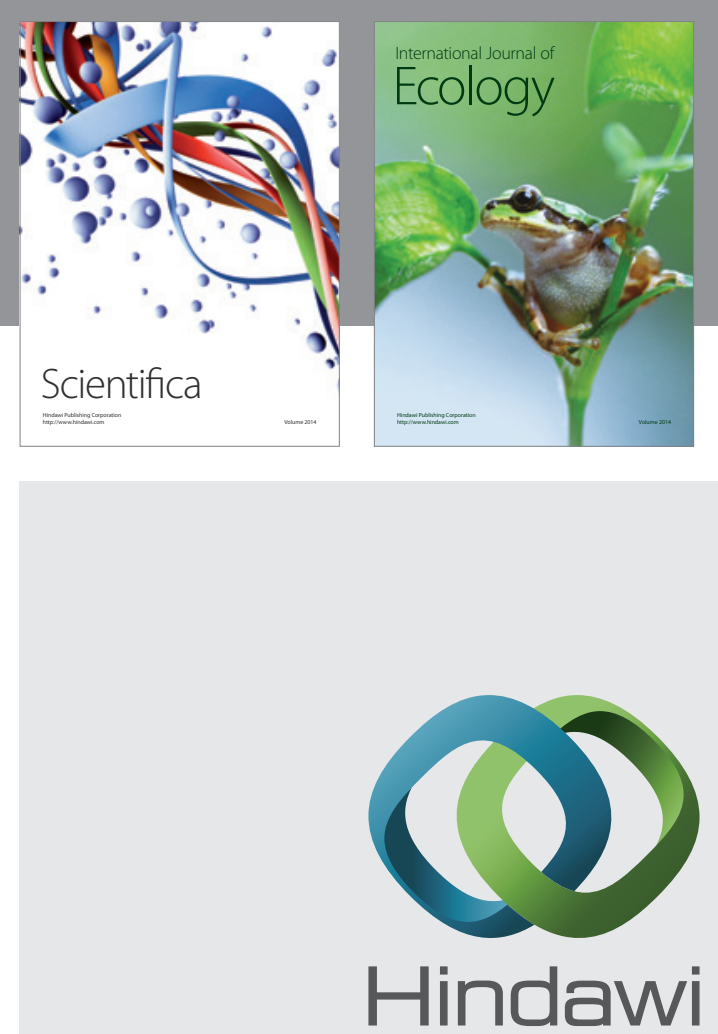

Submit your manuscripts at http://www.hindawi.com
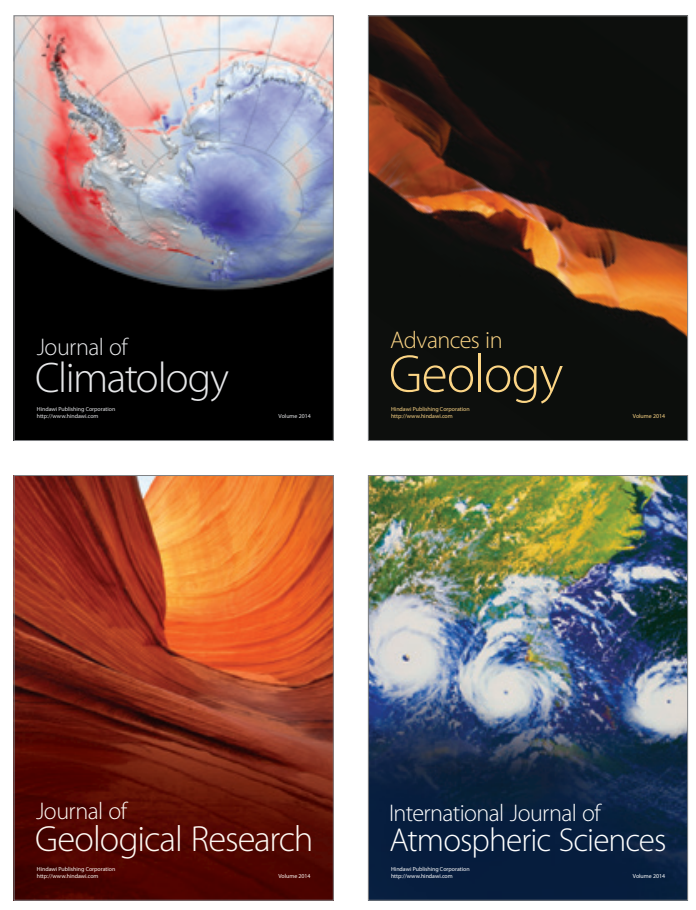
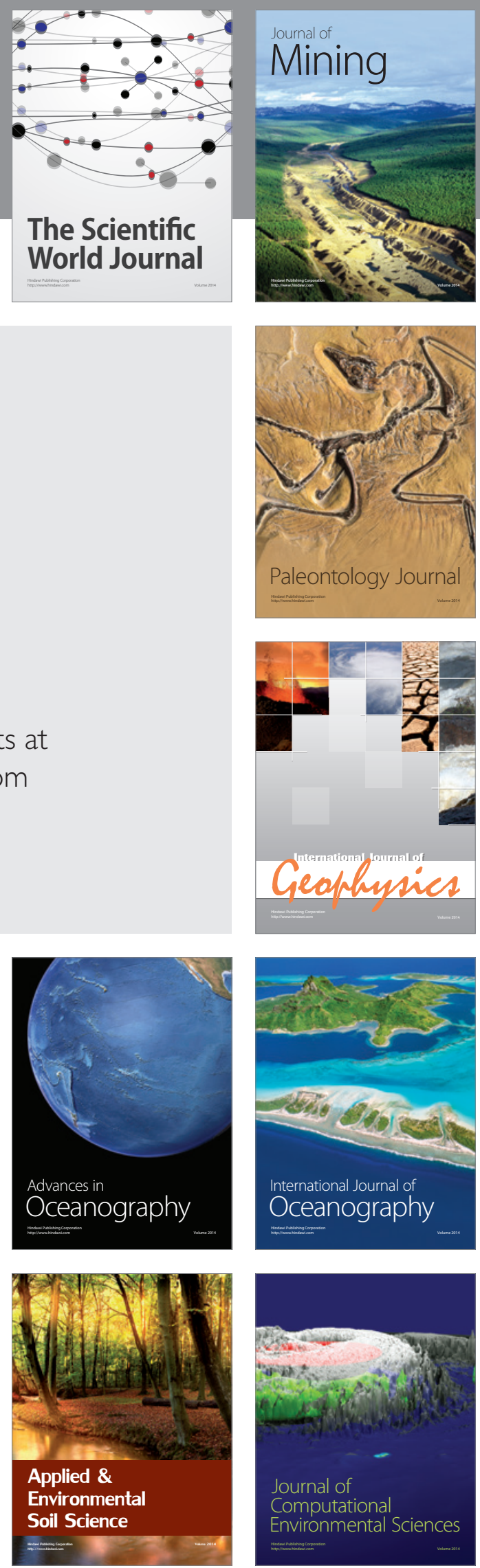